\title{
05
}

\section{Эволюция структуры и механических свойств при отжиге сплава FeNi после мегапластической деформации}

\author{
(C) А.М. Глезер ${ }^{1,2}$, А.А. Томчук ${ }^{2,3}$, В.И. Бетехтин ${ }^{4}$, Би Дунсюэ ${ }^{3}$ \\ ${ }^{1}$ Национальный исследовательский технологический университет \\ „МИСиС“, Москва \\ ${ }^{2}$ Центральный научно-исследовательский институт черной металлургии \\ им. И.П. Бардина, Москва \\ ${ }^{3}$ Московский государственный технический университет \\ им. Н.Э. Баумана \\ ${ }^{4}$ Физико-технический институт им. А.Ф. Иофрфе, Санкт-Петербург \\ E-mail: a.glezer@mail.ru
}

Поступило в Редакцию 26 сентября 2016 г.

Методами просвечивающей электронной микроскопии, дифракции обратно рассеянных электронов и измерения микротвердости проанализирована эволюция структурных параметров и механических свойств сплава FeNi в процессе отжига после мегапластической деформации при комнатной температуре в камере Бриджмена. Показано, что процесс первичной рекристаллизации сопровождается ростом ранее возникших при деформации рекристаллизованных зерен. В то же время деформационные фрагменты не способны к росту, поскольку их границы обладают крайне низкой подвижностью.

DOI: 10.21883/PJTF.2017.08.44538.16484

Экстремальные воздействия оказывают существенное влияние на структуру и свойства твердых тел [1]. К их числу, безусловно, следует отнести воздействие очень больших (мегапластических) деформаций (МПД). За последние годы интерес к этому способу обработки материалов существенно возрос, поскольку он дает возможность существенно повысить физико-механические свойства металлических материалов [2]. В значительной мере это связано с образованием наноструктурных состояний различного вида. Наиболее распространенным способом создания гигантских степеней деформации является кручение под высоким давлением (КВД) в камере Бриджмена [3], 
при котором образец помещается между двумя наковальнями, одна из которых медленно вращается при одновременном создании очень высоких квазигидростатических давлений (несколько GPa). Формирующиеся при столь значительных деформациях структурные состояния весьма необычны. Недавно в работе [4] в рамках энергетической концепции существования дополнительных каналов диссипации (релаксации) упругой энергии при МПД экспериментально было установлено образование в структуре сплава FeNi после МПД в камере Бриджмена при комнатной температуре областей структуры, соответствующих двум структурным составляющим: деформационным фрагментам и динамически рекристаллизованным зернам. Было также установлено [5], что микротвердость и магнитная жесткость подобных „Двухфазных“ сплавов после МПД тем выше, чем выше объемная доля деформационных фрагментов в структуре материала.

Представляет безусловный интерес проследить за эволюцией ,двухфазных“ структур, сформировавшихся в процессе МПД в сплаве $\mathrm{FeNi}$, при последующих термических воздействиях. Проблеме трансформации структуры после нагрева материалов, подвергшихся МПД, посвящен ряд исследований, выполненных для различных металлических систем [6,7], однако в чем принципиальные различия структурных превращений в процессе нагрева материалов после МПД и после обычных макропластических деформаций, остается пока неясным. Этой проблеме и посвящена данная статья.

Для создания МПД в работе была использована камера Бриджмена, в которой реализуется КВД [3]. В качестве материала для исследования был выбран однофазный поликристаллический сплав $50 \mathrm{H}(\mathrm{Fe}-50 \% \mathrm{Ni})$ с кристаллической структурой ГЦК твердого раствора, имевший после медленного охлаждения от $850^{\circ} \mathrm{C}$ средний размер зерна около $50 \mu \mathrm{m}$ и практически полное отсутствие кристаллографической текстуры. Деформации типа КВД при комнатной температуре подвергались тонкие $(0.2 \mathrm{~mm})$ пластинки при постоянной величине квазигидростатического давления $(P=4 \mathrm{GPa})$, скорости вращения подвижного бойка 1 полный оборот в минуту и при числе непрерывных полных оборотов подвижной наковальни $N=1 / 2,1,2,3$ и 4. Последеформационный отжиг образцов, прошедших МПД с различными величинами деформации, проводился в вакуумной печи при температурах $100-500^{\circ} \mathrm{C}$ в течение $0.5 \mathrm{~h}$. Измерения микротвердости $H V$ выполнялись на микротвердомере LECO M-400A при нагрузке $50 \mathrm{~g}$ и времени нагру-

Письма в ЖТФ, 2017, том 43, вып. 8 


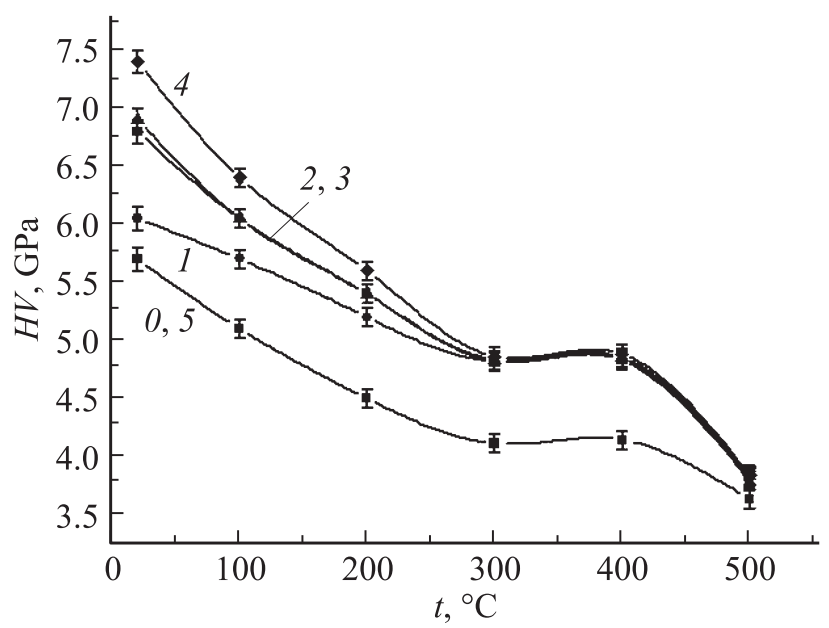

Рис. 1. Влияние температуры отжига $(1 \mathrm{~h}) t$ на значение микротвердости $H V$ в сплаве $\mathrm{FeNi}$ после МПД при комнатной температуре в камере Бриджмена; цифрами обозначено число оборотов $N$ при деформации.

жения $5 \mathrm{~s}$, а также при усреднении конечных результатов после 20 измерений. Структурные исследования проводились после МПД с помощью просвечивающего электронного микроскопа JEM-200CX в режиме светлого и темного поля. В работе использовался также растровый электронный микроскоп JSM-7500F с приставкой для EBSDанализа (метод обратно рассеянных электронов). Шаг сканирования при этом составлял $0.05 \mu \mathrm{m}$. Все исследования структуры проводились в областях, примерно соответствующих половине радиуса дискообразных образцов.

На рис. 1 представлено изменение микротвердости $H V$ после различных режимов МПД и термической обработки. Видно, что различия в значениях $H V$, соответствующих различным величинам МПД, практически полностью исчезают (за исключением $N=0.5$ ) после отжига при $300^{\circ} \mathrm{C}$. Это достигается за счет различия линейных скоростей снижения $H V$ с температурой $d(H V) / d t$, которая тем выше, чем больше значение $N$. При более высоких значениях температуры отжига в интервале $300-400^{\circ} \mathrm{C}$ наблюдается явно выраженное плато (постоян-

6 Письма в ЖТФ, 2017, том 43, вып. 8 


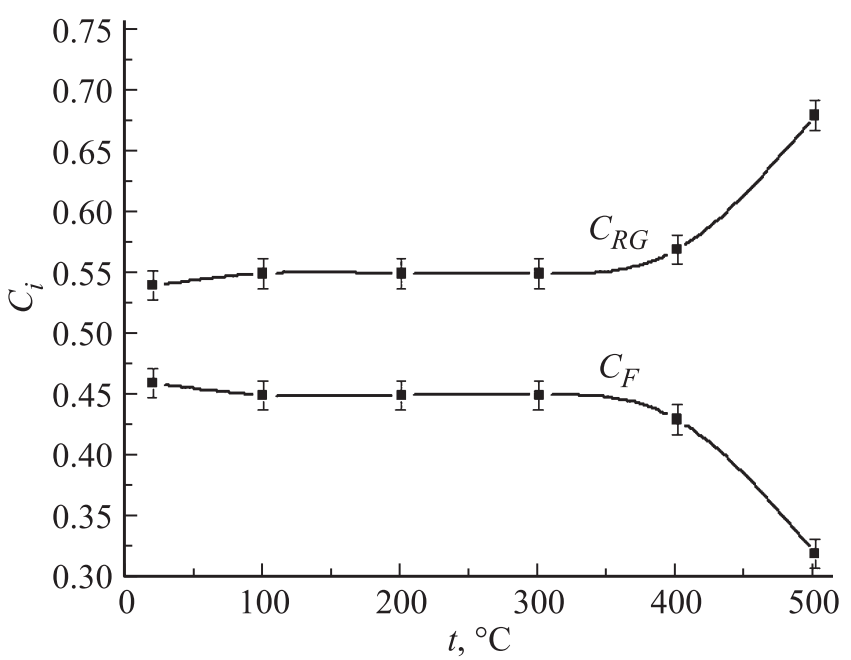

Рис. 2. Влияние температуры отжига $(1 \mathrm{~h}) t$ на объемную долю деформационных фрагментов $C_{F}$ и рекристаллизованных зерен $C_{R G}$ в сплаве $\mathrm{FeNi}$ после МПД при комнатной температуре в камере Бриджмена $(N=4)$.

ство значения $H V$ ), а затем резкое падение со скоростью, примерно соответствующей падению $H V$ при более низких температурах отжига после $N=4$.

На рис. 2 показано изменение по мере роста температуры отжига $t$ объемной доли дислокационных фрагментов $C_{F}$ и рекристаллизованных зерен $C_{R G}$, а на рис. 3 - среднего размера дислокационных фрагментов $D_{F}$ и рекристаллизованных зерен $D_{R G}$. Эти зависимости были получены по результатам исследования методами просвечивающей электронной микроскопии и EBSD-анализа по методике, подробно описанной в работе [8]. На рис. 2 и 3 представлены результаты измерений после деформации $N=4$, но аналогичные зависимости были также получены и после $N=1-3$, для которых исходные значения структурных параметров $C_{i}$ и $D_{i}$ после МПД были примерно такими же [5].

Как следует из представленных зависимостей, после отжига при $t \leqslant 400^{\circ} \mathrm{C}$ каких-либо изменений в значениях структурных параметров $D_{F}$ и $D_{R G}$ не происходит, но появляется тенденция к незна- 


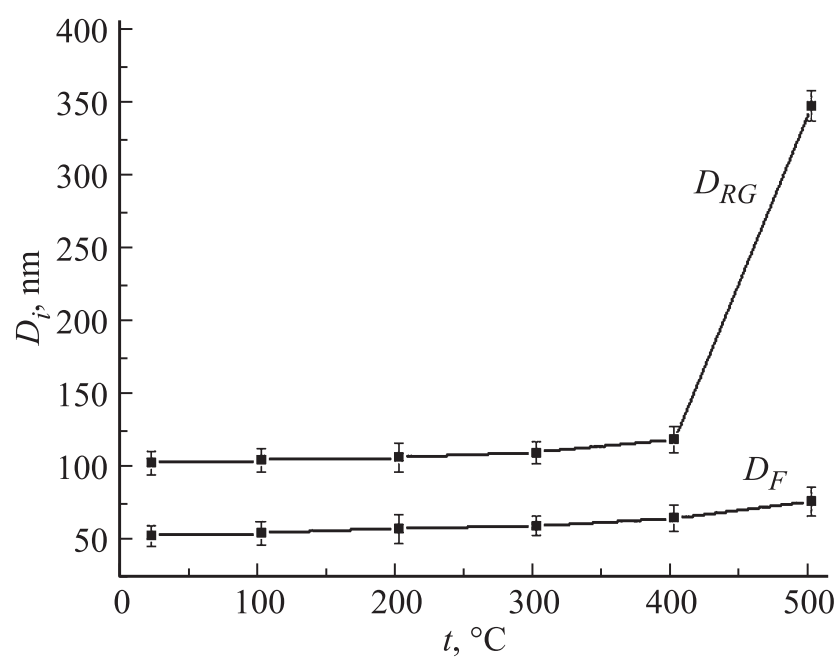

Рис. 3. Влияние температуры отжига $(0.5 \mathrm{~h}) t$ на средний размер деформационных фрагментов $D_{F}$ и рекристаллизованных зерен $D_{R G}$ в сплаве $\mathrm{FeNi}$ после МПД при комнатной температуре в камере Бриджмена $(N=4)$.

чительному снижению $C_{F}$ и к слабому возрастанию значения $C_{R G}$. Разительные изменения в структуре происходят лишь после отжига при $t=500^{\circ} \mathrm{C}$. Происходит резкое возрастание доли рекристаллизованных зерен и соответственно существенное снижение доли дислокационных фрагментов, что по существу соответствует активному протеканию процесса первичной рекристаллизации. Но при этом, как следует из рис. 3, наблюдается рост лишь тех зерен, которые возникли в результате динамической рекристаллизации в процессе МПД (резкое увеличение параметра $\left.D_{R G}\right)$. Что же касается дислокационных фрагментов, то изменения их размеров $\left(D_{F}\right)$ в процессе рекристаллизации практически не происходит.

Наблюдаемое на рис. 1 линейное снижение микротвердости при низких температурах отжига $100-300^{\circ} \mathrm{C}$ (примерно на $10-15 \%$ в зависимости от значения $N$ ) обусловлено, скорее всего, процессами релаксации упругих искажений, возникших при МПД. Эта стадия отдыха [9] не связана с заметной перестройкой структуры. Происходит лишь некоторое снижение плотности дислокаций и незначительное

6* Письма в ЖТФ, 2017, том 43, вып. 8 
упорядочение дефектных структур. Тот факт, что после $N=0.5$ зависимость $H V(t)$ не соответствует зависимостям после других значений МПД, связан, по-видимому, с тем, что при кручении на столь малую величину деформационные процессы в различных областях материала слишком неоднородны и не охватывают в достаточной степени весь объем образцов.

Наблюдаемое на втором этапе изменения $t\left(300-400^{\circ} \mathrm{C}\right)$ плато на зависимости $H V(t)$ (рис. 1) обусловлено, на наш взгляд, тем обстоятельством, что процессы упругой релаксации успели полностью пройти при более низких значениях $t \leqslant 300^{\circ} \mathrm{C}$, а процессы рекристаллизации, связанные с перестройкой границ фрагментов и динамически рекристаллизованных зерен, еще не начались $\left(t>4000^{\circ} \mathrm{C}\right)$. В этом температурном интервале могли бы, по-видимому, активно протекать процессы полигонизации. Но в нашем случае деформационные фрагменты и динамически рекристаллизованные зерна, сформировавшиеся при МПД, практически не содержат хаотично распределенных дислокаций и, следовательно, процесс полигонизации при отжиге фактически отсутствует.

Существенные изменения в структуре, сопровождающиеся практически одинаковым снижением $H V$ для всех величин МПД (за исключением $N=1 / 4$ ), происходят после отжига при $t \geqslant 500^{\circ} \mathrm{C}$. При этих температурах отжига начинаются процессы первичной рекристаллизации, которые приводят к существенному увеличению среднего размера рекристаллизованных зерен $D_{R G}$ (рис. 3). Как видно из того же рисунка, средние размеры дислокационных фрагментов $D_{F}$ почти не изменяются. Это, по существу, означает, что первичная рекристаллизация при отжиге реализуется за счет увеличения размеров динамически рекристаллизованных зерен, возникших в процессе МПД, а деформационные фрагменты в процессе первичной рекристаллизации участия не принимают.

Отмеченные особенности протекания процессов первичной рекристаллизации, безусловно, связаны со спецификой деформационных процессов, реализующихся при МПД. Деформационные фрагменты, формирующиеся при МПД по дисклинационному механизму В.В. Рыбина [10], являются свободными от дислокаций мезодефектами и характеризуются малоподвижными границами, содержащими дисклинационные составляющие, которые не способны к активной миграции. В то же время в структуре материала после МПД имеется другая „фаза“ - динамически

Письма в ЖТФ, 2017, том 43, вып. 8 
рекристаллизованные зерна, обладающие относительно совершенными границами, которые способны к активной миграции. Таким образом, первичная рекристаллизация при отжиге происходит путем миграции границ зерен, возникших при динамической рекристаллизации. Дислокационные фрагменты могут принять участие в этом процессе лишь только после того, как в них произойдет рекристаллизация, но не по механизму миграции границ зерен, а по механизму коалесценции [11]. Подобная модель рекристаллизации в сплавах, прошедших МПД, в корне отличается от представлений, высказанных ранее другими исследователями [7].

Работа выполнена при финансовой поддержке РНФ (грант 15-12-30010), а также в части проведения деформационных экспериментов в камере Бриджмена - при финансовой поддержке МОН РФ (госзадание № 2014/113).

\section{Список литературы}

[1] Глезер А.М., Столяров В.Л. и др. // Письма в ЖТФ. 2016. Т. 42. В. 1. С. 103.

[2] Valiev R.Z., Estrin Yu. et al. // JOM. 2006. V. 58. P. 33.

[3] Zhilyaev A.P., Langdon T.G. // Progr. Mater. Sci. 2008. V. 53. P. 893.

[4] Glezer A.M., Tomchuk A.A. et al. // Mat. Lett. 2015. V. 161. P. 360.

[5] Glezer A.M., Varyukhin V.N. et al. // Bull. Russian Acad. Sci. Phys. 2014. V. 78. P. 1022.

[6] Нохрин А.В. // Деформация и разрушение материалов. 2012. № 12. С. 19.

[7] Утяшев Ф.3., Рааб. Г.И. Деформационные методы получения и обработки ультрамелкозернистых и наноструктурных материалов. Уфа: Гилем, 2013. $376 \mathrm{c}$.

[8] Electron Backscatter Diffraction in Materials Science. / Ed. by A. Schwartz, M. Kumar, B.L. Adams, D.P.O. Field. N.Y.: Springer, 2009. 544 p.

[9] Горелик С.С., Добаткин С.В., Капуткина Л.М. Рекристаллизация металлов и сплавов. М.: МИСиС, 2005. $432 \mathrm{c.}$

[10] Рыбин В.В. Большие пластические деформации и разрушение металлов. М.: Металлургия, 1986. 224 с.

[11] Humphreys F.J., Hatherly M. Recrystallization and related annealing phenomena. Amsterdam: Elsevier, 2004. 620 p.

Письма в ЖТФ, 2017, том 43, вып. 8 